\title{
Surgical Treatment of T1-2 Disc Herniation with T1 Radiculopathy: A Case Report with Review of the Literature
}

\author{
Eun-Seok Son ${ }^{1}$, Sang-Hun Lee ${ }^{2}$, So-Young Park ${ }^{3}$, Ki-Tack Kim² ${ }^{2}$ Chul-Hyung Kang ${ }^{1}$, Seong-Woo Cho ${ }^{2}$ \\ ${ }^{1}$ Department of Orthopedic Surgery, Keimyung University School of Medicine, Daegu, Korea \\ ${ }^{2}$ Department of Orthopedic Surgery, Kyung Hee University School of Medicine, Seoul, Korea \\ ${ }^{3}$ Department of Radiology, Kyung Hee University School of Medicine, Seoul, Korea
}

\begin{abstract}
The prevalence of intervertebral disc herniation (IDH) of the thoracic spine is rare compared to the cervical or lumbar spine. In particular, IDH of the upper thoracic spine is extremely rare. We report the case of T1-2 IDH and its treatment, with a literature review. A 37 -year-old male patient visited our hospital due to radiating pain at the left upper extremity and weakness of grip power. In cervical spine magnetic resonance images, T1-2 disc space showed herniated disc material and compressed $\mathrm{T} 1$ root was identified. Laminoforaminotomy was performed with a posterior approach. The radiating pain and weakness of grip power improved immediately after the surgery. Of patients who show radiating pain or numbness at the medial aspect of forearm, or weakness of intrinsic muscle of hand, can be suspected to have T1 radiculopathy. A detailed physical examination and a radiologic evaluation including this area should be required for the T1 radiculopathy.
\end{abstract}

Key Words: Thoracic Vertebrae, Intervertebral Disc, Radiculopathy, Laminotomy

\section{Introduction}

The prevalence of intervertebral disc herniation of the thoracic spine is rare compared to that of the cervical or lumbar spine. In particular, intervertebral disc herniation of the upper thoracic spine is extremely rare $[1,2]$. Since Svien and Karavitis [3] reported one case in 1954, 39 cases of T1-2 disc have been reported to date, of which 19 cases had no individual description as they were included with reports on thoracic disc herniation, and 20 cases had descriptions of each case and surgical treatment as they were case reports (Table 1) [3-18]. In some of the aforementioned cases, the diagnosis and treatment of the disease was delayed as patients were misdiagnosed with medical diseases or other spinal diseases in the early diagnosis. In the present report, the patient was also misdiagnosed with other level intervertebral disc herniation in the early diagnosis, but he was shown to have T1-2 herniated nucleus pulposus (HNP) during the treatment. Accordingly, the authors report this case with a literature review.

\section{Case Report}

A 37-year-old male patient visited our hospital due to radiating pain at the left upper extremity and weakness of grip power. The symptoms of the patient occurred five days before the visit without particular trauma history. The patient underwent conservative management including medication at a local clinic, but the symptoms were aggravated. A physical examination showed pain at the left scapular area, radiating pain at the medial aspect of forearm and at the fourth and fifth fingers, approximately $70 \%$ of sensory loss compared to the unaffected side, decreased left hand grip power with motor grade IV, and positive Spurling sign.

Received May 2, 2011; Revised May 2, 2011; Accepted May 16, 2011

Corresponding author: Sang-Hun Lee, MD

Department of Orthopedic Surgery, Spine Center, Kyung Hee University Hospital at Gangdong,

892 Dongnam-ro, Gangdong-gu, Seoul 134-727, Korea

Tel: +82-2-440-6152, Fax: +82-2-440-7498, E-mail: shl6@khu.ac.kr 
Table 1. Summary of literature review on T1-2 HNP

\begin{tabular}{|c|c|c|c|c|}
\hline Author (Year) & Age $(y r) / \operatorname{Sex}$ & Site & $\mathrm{Sx}$ & Operative procedure \\
\hline Svien and Karavitis (1954) [3] & $39 / \mathrm{M}$ & $\mathrm{Lt}$ & $\mathrm{RP}$ & Hemilaminectomy \\
\hline Horwitz et al. (1955/6) [4] & $43 / \mathrm{F}$ & Rt & $\mathrm{RP}$ & Hemilaminectomy \\
\hline Abbott and Retter (1955) [5] & $61 / \mathrm{M}$ & $\mathrm{Rt}$ & $\mathrm{RP}$ & Hemilaminectomy \\
\hline Hammon (1968) [6] & $33 / \mathrm{M}$ & $\mathrm{Lt}$ & $\mathrm{RP}$ & Hemilaminectomy \\
\hline Gelch (1978) [7] & $40 / \mathrm{M}$ & Rt & $\mathrm{RP}$ & Partial laminectomy \\
\hline Patterson and Arbit (1978) [8] & $39 / \mathrm{M}$ & $\mathrm{C}$ & MP & Facectectomy \& laminectomy \\
\hline Hann (1980) [9] & $\begin{array}{l}43 / \mathrm{M} \\
43 / \mathrm{F}\end{array}$ & $\begin{array}{l}\mathrm{Lt} \\
\mathrm{Lt}\end{array}$ & $\begin{array}{l}\mathrm{RP} \\
\mathrm{RP}\end{array}$ & Semi-hemilaminectomy \\
\hline Lloyd et al. (1980) [10] & $50 / \mathrm{M}$ & $\mathrm{Lt}$ & $\mathrm{RP}$ & Laminectomy \\
\hline Alberico et al. (1986) [11] & 49/M & Rt & $\mathrm{RP}$ & Posterolateral appraach \\
\hline Kumar and Buckley (1986) [12] & $45 / \mathrm{M}$ & $\mathrm{Rt}$ & $\mathrm{RP}$ & Hemilaminectomy \\
\hline Hamlyn et al. (1991) [13] & $72 / \mathrm{F}$ & Rt & $\mathrm{RP}$ & Partial laminectomy \\
\hline Rossitti et al. (1993) [14] & $43 / \mathrm{M}$ & Rt & $\mathrm{RP}$ & Anterior decompression \& fusion \\
\hline Winter and Siebert (1993) [15] & $66 / F$ & $\mathrm{C}$ & MP & $\begin{array}{l}\text { Trans-thoracic approach } \\
\text { (T2 subtotal corpectomy) }\end{array}$ \\
\hline Nakahara and Sato (1995) [16] & $56 / \mathrm{M}$ & $\mathrm{C}$ & MP & Anterior decompression \& fusion \\
\hline Morgan and Abood (1998) [17] & $\begin{array}{c}69 / \mathrm{F} \\
48 / \mathrm{M} \\
54 / \mathrm{M} \\
48 / \mathrm{M}\end{array}$ & $\begin{array}{l}\mathrm{Rt} \\
\mathrm{Lt} \\
\mathrm{Lt} \\
\mathrm{Lt}\end{array}$ & $\begin{array}{l}\text { RP } \\
\text { RP } \\
\text { RP } \\
\text { RP }\end{array}$ & Laminoforaminotomy \\
\hline Caner et al. (2003) [18] & $57 / \mathrm{M}$ & $\mathrm{Lt}$ & $\mathrm{RP}$ & Anterior discectomy (manubrium split) \\
\hline Our case & $37 / \mathrm{M}$ & $\mathrm{Lt}$ & $\mathrm{RP}$ & Laminoforaminotomy \\
\hline
\end{tabular}

HNP: Herniated nucleus pulposus, Sx: Symptom, Lt: Left, RP: Radiculopathy, Rt: Right, MP: Myelopathy, C: Central.

No myelopathic symptom and Horner's syndrome such as ptosis, enopthalmus, and anhydrosis were observed. No difference in biceps jerk and triceps jerk was found between the affected and unaffected sides. No pathologic reflex such as Hoffmann sign and inverted radial reflex was found.
Cervical spine simple radiographs examination showed no particular finding except mild kyphosis. The patient was suspected to have disc herniation of the cervical spine, and underwent cervical spine magnetic resonance images (MRI). The MRI examination showed mild neural compression at
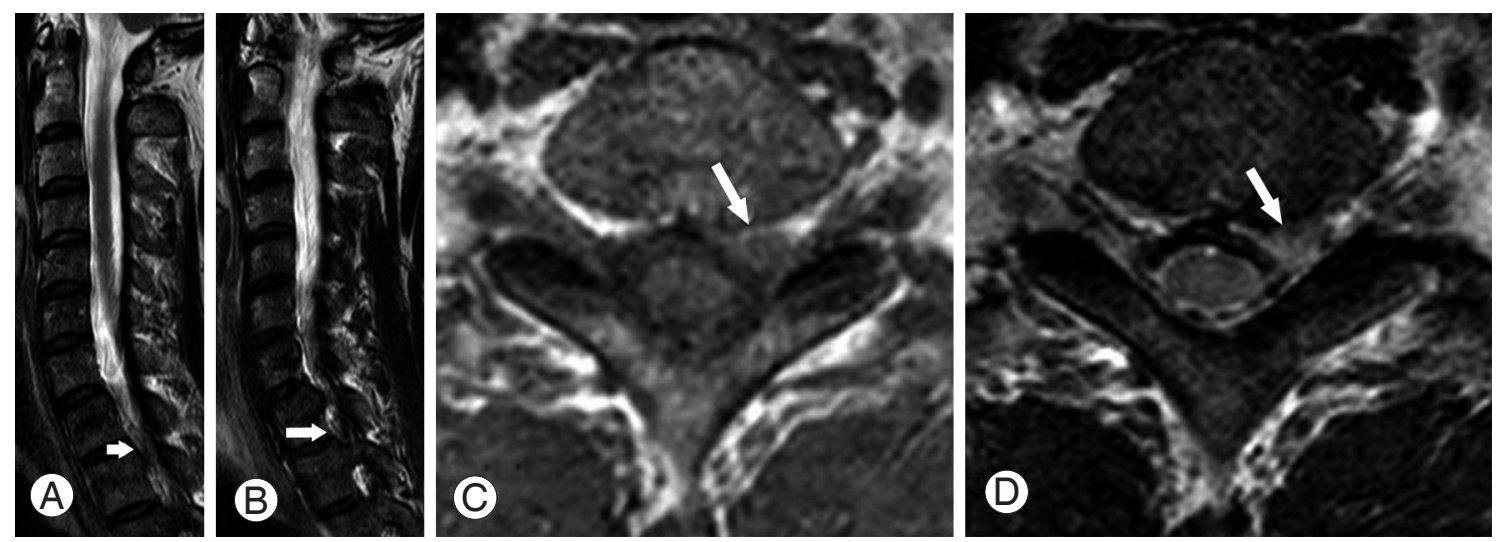

Fig. 1. Preoperative T2 sagittal $(\mathbf{A}, \mathbf{B})$ and thin section $\mathrm{T} 1$ and $\mathrm{T} 2$ axial $(\mathbf{C}, \mathbf{D})$ magnetic resonance images on T1-2 disc level show the ruptured disc fragment (arrows) with distal migration. 
Table 2. Summary of the symptoms and signs (T1-2 HNP in literature review) $(n=21)$

\begin{tabular}{lc}
\hline \multicolumn{1}{c}{ Symptoms and signs } & No. of cases (\%) \\
\hline Radiating pain (on the medial aspect of the arm and 4th, 5th fingers) & $18(86)$ \\
Axial pain (on the neck and scapular area) & $17(81)$ \\
Sensory deficit (T1 dermatome) & $15(71)$ \\
Motor deficit (intrinsic muscles of hand) & $14(67)$ \\
Horner's syndrome & $7(33)$ \\
Chest pain & $5(24)$ \\
Myelopathy & $3(14)$ \\
\hline
\end{tabular}

HNP: Herniated nucleus pulposus.

the left C6-7 foramen. Subsequently, selective nerve root block on left $\mathrm{C} 7$ was performed for both diagnosis and treatment. After the selective nerve root block, the patient showed almost no improvement of the symptoms. After detailed review of the MR images, herniation of intervertebral disc on T1-2 level was suspected at the distal end of images. Rechecked MRI on this area showed intervertebral disc herniation that compressed T1 root (Fig. 1). As the patient suffered from severe radiating pain with weakness and numbness, a surgical treatment was planned. As the disc was extruded to the posterolateral side, and no compression of the spinal cord was found, decompression surgery via a posterior approach was planned. Laminoforaminotomy was performed with prone position and we could remove the subligamentous disc that compressed T1 root (Fig. 2). Most symptoms of radiating pain and weakness improved immediately after the surgery. The patient recovered without any complication for six months after the surgery.
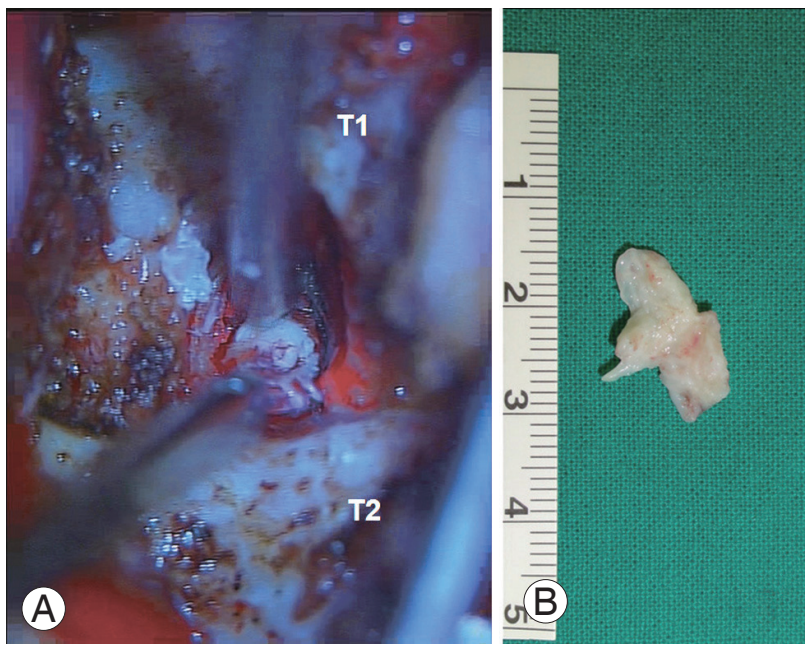

Fig. 2. Intraoperative photograghs. (A) After the laminoforaminotomy on the left side of T1-2 facet joint, a ruptured fragment compressing T1 nerve root was removed. (B) Removed subligamentous extruded disc.

\section{Discussion}

Herniation of intervertebral disc or stenosis rarely occurs at T1-2 level. This area is generally obscured by the shoulder in X-ray examination, and commonly located at the caudal end in computed tomography (CT) or MRI examination. Thus, it is difficult to observe this area carefully. Accordingly, when this area has a lesion, it is frequently misdiagnosed with medical diseases or other level herniation of intervertebral disc as shown in this case, and sometimes, it is identified during the treatment [11]. In the case of T1-2 disc herniation, spinal cord or T1 root compression occurs. T1 root is a root comprising the brachial plexus, and constitutes the ulnar nerve along with $\mathrm{C} 8$ root. Thus, $\mathrm{T} 1$ radiculopathy may accompany numbness of the fourth and fifth fingers, or weakness of intrinsic muscle of hand as similar to C8 radiculopathy. As symptoms similar to the aforementioned symptoms may be observed if the entrapment of the peripheral nerve, such as cubital tunnel syndrome or Guyon's tunnel syndrome, it is important to correctly identify the lesion location. According to previous reports, radiating pain at medial aspects of the forearm and at fourth and fifth fingers, and axial pain at the neck and periscapular area were reported to occur with a frequency of $86 \%$ and $81 \%$, respectively, for T1-2 disc herniation (Table 2). T1 radiculopathy may accompany Horner's syndrome. In this case, level of neural compression can be more easily predicted, but diseases such as pancoast tumor and intrathoracic neoplasm should be ruled out [10]. Although upper thoracic disc herniation has been known to rarely occur, but relatively commonly occur at T1-2 level among the upper thoracic levels [17,19]. The literature review showed that a majority of patients had only radiculopathy, and underwent laminectomy or foraminotomy via a posterior approach, and achieved a good outcome $[3,10,17,19]$. Taken together, successful treatments were achieved using posterior laminotomy and/or foraminotomy in $17(81 \%)$ out of 21 cases. Meanwhile, an anterior ap- 
proach was applied in four cases (19\%) showing myelopathy due to the compression of the spinal cord by central disc herniation. Some studies reported that successful treatments were achieved using Southwick-Robinson approach without sternotomy, but others reported that partial sternotomy was required $[14,16,18]$. Therefore, when a surgical treatment using an anterior approach is planned, the relationship between the sternum and T1-2 level should be considered before surgery, and an appropriate procedure should be prepared if sternotomy is required.

T1-2 level is a region that is not observed closely in cervical spinal radiographs or MRI. Of patients who show radiating pain or numbness at the medial aspect of the forearm, or weakness of the intrinsic muscle of the hand, those who have non-typical results in physical examination, or who had an effect less than expected after selective nerve root block on the lower cervical spine are suspected to have T1 radiculopathy. A delicate physical examination and a radiologic evaluation including this area and treatment plan are required for the aforementioned patients.

\section{REFERENCES}

1. Arseni C, Nash F. Thoracic intervertebral disc protrusion: a clinical study. J Neurosurg 1960;17:418-30.

2. Murphey F, Simmons JCH, Brunson B. Surgical treatment of laterally ruptured cervical disc: review of 648 cases, 1939 to 1972. J Neurosurg 1973;38:679-83.

3. Svien HJ, Karavitis AL. Multiple protrusions of intervertebral disks in the upper thoracic region: report of case. Proc Staff Meet Mayo Clin 1954;29:375-8.

4. Horwitz NH, Whitcomb BB, Reilly FG. Ruptured thoracic discs. Yale J Biol Med 1955/1956;28:322-30.

5. Abbott KH, Retter RH. Protrusions of thoracic intervertebral disks. Neurology 1956;6:1-10.

6. Hammon WM. Extruded upper thoracic disc causing Horner's syndrome: report of a case. Med Ann Dist Co- lumbia 1968;37:541-2.

7. Gelch MM. Herniated thoracic disc at T1-2 level associated with Horner's syndrome: case report. J Neurosurg 1978;48:128-30.

8. Patterson RH Jr, Arbit E. A surgical approach through the pedicle to protruded thoracic discs. J Neurosurg 1978;48:768-72.

9. Hann EC. Experience with ruptured T1-T2 discs. J Indiana State Med Assoc 1980;73:598-9.

10. Lloyd TV, Johnson JC, Paul DJ, Hunt W. Horner's syndrome secondary to herniated disc at T1-T2. AJR Am J Roentgenol 1980;134:184-5.

11. Alberico AM, Sahni KS, Hall JA Jr, Young HF. High thoracic disc herniation. Neurosurgery 1986;19:449-51.

12. Kumar R, Buckley TF. First thoracic disc protrusion. Spine (Phila Pa 1976) 1986;11:499-501.

13. Hamlyn PJ, Zeital T, King TT. Protrusion of the first thoracic disk. Surg Neurol 1991;35:329-31.

14. Rossitti S, Stephensen H, Ekholm S, von Essen C. The anterior approach to high thoracic (T1-T2) disc herniation. Br J Neurosurg 1993; 7:189-92.

15. Winter RB, Siebert R. Herniated thoracic disc at T1-T2 with paraparesis: transthoracic excision and fusion, case report with 4-year follow-up. Spine (Phila Pa 1976) 1993;18:782-4.

16. Nakahara S, Sato T. First thoracic disc herniation with myelopathy. Eur Spine J 1995;4:366-7.

17. Morgan H, Abood C. Disc herniation at T1-2: report of four cases and literature review. J Neurosurg 1998;88:148-50.

18. Caner H, Kilinçoglu BF, Benli S, Altinörs N, Bavbek M. Magnetic resonance image findings and surgical considerations in T1-2 disc herniation. Can J Neurol Sci 2003;30:152-4.

19. Love JG, Schorn VG. Thoracic disk protrusions. JAMA 1965;191:627-31. 